\title{
Preparing For The FFAEM examination
}

\author{
D Sharma
}

\section{Introduction}

The Fellowship of the Faculty of Emergency Medicine Examination is the exit examination for trainees in Emergency Medicine, taken at the end of their specialist registrar programme. The following article is based on the author's recent personal experience of the examination before taking up a consultant post. The examination has only recently been introduced and experience is still limited but the opinions of others who have taken it have been incorporated, both from direct questioning and from courses attended.

\section{Administration}

Regulations and entry forms can be obtained by post from the Faculty of Accident and Emergency Medicine at 35-43 Lincoln's Inn Fields, London, WC2A 3PN (tel. 020 74057071) or from the web site at http://www.faem.org.uk

\section{Eligibility}

As stated above, the examination is an exit examination for those undergoing training in Emergency (formerly Accident and Emergency) Medicine. Specialist registrar training in Emergency Medicine takes a minimum of five years. The exit examination (FFAEM) is taken after the fourth year RITA. Proof of successful completion of this is required.

\section{Examination Timing and Venues}

The examination is held twice a year; the location is rotated around various British cities. A full application form is required to be submitted before the published closing date, approximately ten weeks before the examination. A considerable amount of paperwork is involved; along with the relevant forms (and cheque) three copies of the Training Record are required as well as three copies of clinical topic review (written review of relevant clinical subjects, see below). At the Fourth Year RITA before the examination it is essential to remember to get the application form signed by course director (noting that there are two separate places on the forms for him or her to sign).

\section{Format}

There are four components to the examination. Depending on the number of candidates the components may be held on separate days (it is unlikely that it would be necessary to spread it over more than two days). The components are:

- Questions and discussion of the clinical topic reviews.

- Review of published work (critical appraisal).

- Objective Structured Clinical Examination (OSCE).

- Accident and Emergency Management viva.

\section{Questions and discussion of the clinical topic reviews}

Two clinical topic reviews are presented with the application for the examination; they should be 2,500- 3,000 words long. They are reviews of the published knowledge about areas relevant to clinical practice and it is not necessary to include original research performed by the submitting candidate. Indeed, if one's own original work is included, its place relative to the other work in this area must be explained and will form the basis of the discussion.

A literature review should be performed and the method of any electronic searches should be included in the text. The search strategy should be known in great detail, and also the reasons for including or omitting the various references. The ability to defend the choice of methodology, style of presentation and recommendations forms a major part of the assessment. It is essential to know the references thoroughly. It is permitted to take copies of the reviews into the examination.

There are generally two examiners; each will take one of the reviews. Fifteen minutes is spent on each clinical topic review. The discussion may be preceded by a short discussion of one's training record.

\section{Review of published work (critical appraisal)}

One hour is allowed to review a recently published paper of relevance to Emergency Medicine. Any abstract or summary will have been removed from the paper. Notes can be made and can be taken into the viva.

Whilst in-depth knowledge of statistics is not required, some knowledge of basic statistics is essential. Two examiners are present and generally ask questions for ten minutes each.
E-mail:

Devsharm@aol.com 
The first task is generally to present an abstract of the paper and this should be prepared before going into the viva. Answers to likely questions such as the logical sequence from literature review to the establishment of a hypothesis, the soundness of the results based on the methodology and the validity of the conclusions based on the results should also be prepared. Strengths and weaknesses of the design and discussion should be identified, as should the potential impact on current clinical positions and understanding. Suggestions for further clinical research may be requested by the examiners. All this comes much more easily if it is regularly practised beforehand; a list of papers that have been used in previous exams is provided at the end of this paper (ANNEX 1).

\section{Objective Structured Clinical Examination (OSCE)}

This section consists of twelve questions lasting five minutes each. Clinical scenarios, radiographs, electrocardiographs and the results of clinical examinations may be presented. An attempt is made to show the breadth of clinical experience required for Emergency Medicine and questions on medical, surgical and paediatric topics will all appear. The questions are detailed and the entire five minutes will be spent writing. There is no time to make up on later stations and there is no opportunity either; a separate piece of paper is used at each station and is taken away after the question is answered.

\section{Accident and Emergency Management Viva}

Again there are two examiners in this viva which lasts forty-five minutes. Each examiner takes half the period of time allocated. The viva starts with an in-tray exercise where a number of documents are awaiting attention at the start of a busy day. The candidate's task is to prioritise them appropriately. The examiners may interrupt with various distractions such as telephone calls while the candidate is preparing, simulated incidents in the waiting room and others. After this, a page with a typed scenario on it will be provided. Questions will be based on this scenario, which will be developed during the viva. A number of short questions on management topics follow this section.

In many ways this is the most stressful oral, it is also longer at forty-five minutes than most postgraduate examination vivas. In addition the questions are about areas which are less familiar to most registrars.

\section{Strategic Concepts}

By the time this examination is taken the candidate will have already passed a postgraduate examination and will appreciate the importance of thorough preparation prior to the examination. This examination requires, if anything, more prior preparation than those previously encountered. Each critical topic review requires a considerable amount of time and must be both prepared well in advance and known thoroughly. If they have been prepared well in advance of the examination (as is be desirable) they should be updated before submission. In addition, a day or two before the examination the literature search should be repeated and any new references examined to avoid surprises courtesy of the examiners. All references quoted in the critical topic review must be read in the original (the Royal Army Medical College library is invaluable for this. One can e-mail lists of references from Medline and the library will send photocopies of the reference and on occasion entire books). A photocopy of the abstracts of the references used can be helpful to while away the evening before the examination.

In order to attend necessary courses it is essential to plan sufficiently in advance. A management course should be attended. The Royal London Hospital runs the only management course specific for Emergency Medicine. Unfortunately there is only one course a year and there is a long waiting list. Application is necessary a few years before the course one wishes to attend! The author was unable to attend this course but attended a management course run by the University of Keele, which was very helpful.

Nearer the examination, a course on the FFAEM examination itself may well be helpful. These are relatively scarce at present but it is likely that more will be organised in the future. A list of recommended courses is given in ANNEX 2.

\section{Suggested Reading}

It is impossible to give a comprehensive list for this type of exam, there are many alternatives to the suggested titles below but topics covered should include those given below.

\section{Management Essential:}

The Consultant's Handbook. Central Consultants and Specialists Committee. British Medical Association. 4th Edition. December 2000 (or at www.bma.org.uk). This was very helpful for complaints procedures, disciplinary action against doctors, clinical governance etc.

Duties of a Doctor (GMC Handbooks)- Good Medical Practice, Advertising, Confidentiality, HIV and AIDS: the ethical considerations. GMC October 1995.

The Way Ahead 1998. British association of Emergency medicine (Tel: 0207831 4050318). October 1998. 
Stress in Accident and Emergency Medicine. British association of Emergency medicine (Tel: 0207831 4050318). August 1999.

Guidance on Contracts and Workload for Consultants in Accident and Emergency Medicine. British association of Emergency medicine (Tel: 0207831 4050318). August 1999.

Management for Doctors. Ed. Jenny Smith, Richard Smith. BMJ Publishing Group. Pub.1995.

Legal Problems in Emergency Medicine. Alan Montague. Oxford Handbooks in Emergency Medicine series. Oxford University Press, Oxford 1996.

\section{Recommended}

MDU Handbooks - Consent to Treatment, Inquests. MDU (free to members, Tel: 0161 428 1234).

A Health Service of all the Talents: Developing the NHS workforce. Consultation document on the review of workforce planning. Department of Health (copies free from Department of Health PO Box 777, London SE1 6XH).

The NHS Plan. A plan for investment. A plan for reform. July 2000. Can be printed from web site www.nhs.uk/nhsplan.

Copies of the Management Issues from backdated copies of the Journal of Accident and Emergency Medicine (from 1996). June 2000 .

\section{Critical Appraisal}

How to Read a Paper. The basics of evidence based medicine. Trisha Greenhalgh. BMJ books 2nd Ed. 2001- if you know this well it should be sufficient in this area.

The Evidence Based Medicine Workbook. Robert A Dixon, James F Munro, Paul B Silcocks. Butterworth Heinemann 1997useful sections on types of study, statistics, the question and answer format provides good practice.

The Pocket Guide to Critical Appraisal. Iain K Crombie. BMJ Publishing Group1996 short and easy to read but probably not sufficient in itself.

\section{Clinical}

It is impossible to be prescriptive here and much will depend on the clinical background of each individual candidate, but some suggested titles are given below:

Diagnostic picture tests in clinical medicine 1-4. Chessell GSJ, Jamieson MJ, Morton RA, Petrie JC, Towler HMA. Wolfe Medical Publications Ltd.

Rapid ECG interpretation. M Gabriel Khan. Saunders 1997.

ECG interpretation for Emergency Medicine a self-assessment guide. Morris F, Jenkins RC, Ahmed JM, Crossman DC. Butterworth Heinemann 1998.

Self-Assessment in Accident and Emergency Medicine. Burke D, Greaves I, Hormbrey P.
Butterworth Heinemann 1996.

ATLS, ALS, APLS manuals.

$\mathrm{X}$-Ray question books- any would be helpful.

\section{Personal Administration}

After applying for the examination, an examination timetable and a list of suggested hotels will be sent out. It is obviously not essential to use these hotels but it would be sensible to book a hotel well in advance. Likewise it is best to pack well in advance, remembering that it is largely an oral examination and that standards of dress are important. It would seem unnecessary to point this out but at a recent sitting two candidates forgot to pack their shoes. One managed to find a 24 hour shopping centre and bought a pair of shoes and the second wore brown shoes with his dark blue suit.

Due to the concern that it would be possible to pass the FFAEM without passing the clinical component of the exam the following revisions have been proposed:

a. The management viva should remain unchanged and should continue to represent $25 \%$ of the overall mark.

b. The clinical topic review (CTR) and critical appraisal section should be combined, only one CTR being required. The viva would not only examine the CTR but also asses the candidate's appraisal of one referenced paper. This section would be worth $25 \%$ of the overall marks.

c. The clinical component would include a revised OSCE section with some assessing "attitudinal" aspects. An additional knowledge assessment would be considered. This section would be worth $50 \%$ of the marks and a pass would be required to pass overall.

It is proposed that the first diet of the revised examination will take place in November 2003.

\section{Summary}

While the pass rate for this examination is relatively high compared to previous postgraduate examinations such as membership or fellowship (of whichever college) it should still not be underestimated. It is true that those who have been through a recognised training scheme should pass and failure reflects upon the scheme as well as the candidate, but the consequences of failure are high and fall directly only upon the candidate.

Thorough preparation will immensely improve the chances of passing first time and finishing the critical topic reviews well in advance is thoroughly recommended (it would be ideal to do one each year during the first four years of training and then choose the best two for the examination). This will leave time to go through the management books and as many short clinical questions books as possible, those designed for MRCP are especially helpful. While the amount of 
reading for the critical appraisal section is relatively short it is essential to practice appraising papers and those previously used are most appropriate for this.

Since the examination is new advice can be difficult to obtain. An FFAEM course is immensely helpful as it allows the opportunity to ask questions of those who have recently passed the examination.

\section{ANNEX 1 Critical Appraisal papers previously used}

1. A treatment algorithm for pneumothoraces complicating central venous catheter insertion. Laronga C, Meric F, Truong MT, Mayfield C, Mansfield P. The American fournal of Surgery. 2000; 180: 523- 526.

2. Prediction of short- and long-term outcomes by troponin $\mathrm{T}$ levels in low-risk patients evaluated for acute coronary syndromes. Peacock IV WF, Emerman CL, Mcerlean ES, Deluca SA, van Lente F, Rao JS, Nissen SE. Annals of Emergency Medicine. 2000; 35(3): 213-220.

3. Radial head subluxations: comparing two methods of reduction. Mcdonald et al. Academic Emergency Medicine 1999; 6(7).

3. Schuckman H, DeJulius D, Blanda M, Gerson LW, DeJulius AJ, Rajaratnam M. Comparison of intramuscular triamcinolone and oral prednisone in the outpatient treatment of acute asthma: a randomized controlled trial. Annals of Emergency Medicine. 31(3): 333-8, 1998.

4. Lin RY, Pesola GR, Bakalchuk L, Morgan JP, Heyl GT, Freyberg CW, Cataquet D, Westfal RE. Superiority of ipratropium plus albuterol over albuterol alone in the emergency department management of adult asthma: a randomized clinical trial. Annals of Emergency Medicine. 31(2): 208-13, 1998.

5. Schiodt FV, Rochling FA, Casey DL, Lee WM. Acetaminophen toxicity in an urban county hospital. New England fournal of Medicine. 337(16): 1112-7, 1997.
6. Todd KH, Hoffman JR, Morgan MT. Effect of cardiologist ECG review on emergency department practice. Annals of Emergency Medicine. 27(1): 1621, 1996.

7. McLauchlan CA, Jones K, Guly HR. Interpretation of trauma radiographs by junior doctors in accident and emergency departments: a cause for concern? Emergency Medicine fournal. 14(5): 295-8, 1997.

8. Bozeman WP, Hexter D, Liang HK, Kelen GD Esophageal detector device versus detection of endtidal carbon dioxide level in emergency intubation. Annals of Emergency Medicine. 27(5): 595-9, 1996.

9. Kelso TM, Self TH, Rumbak MJ, Stephens MA, Garrett W, Arheart KL. Educational and long-term therapeutic intervention in the ED: effect on outcomes in adult indigent minority asthmatics. American fournal of Emergency Medicine. 13(6): 6327, 1995.

10. Scarfone RJ,Loiselle JM, Wiley JF 2nd, Decker JM, Henretig FM, Joffe MD. Nebulized dexame-thasone versus oral prednisone in the emergency treatmen of asthmatic children. Annals of Emergency Medicine. 26(4):480-6, 1995.

\section{ANNEX 2 Recommended}

\section{Courses}

1. Leeds workshop on critical appraisal for staff from acute specialties. Dr Richard Hardern/Dr P Ayres. Contact: Dept of Clinical Audit, St fames University Hospital, Leeds. Tel: 0113 2433144. Fax: 0113 2064099.

2. Managing an Accident and Emergency Department. Mr S Miles. The Royal London Hospital. Tel: 02073777000.

3. Clinical Management Course for Specialist Registrars in Surgical Specialties. Clinical Management Unit, Keele University. Tel: 01782 621111.

4. Chelsea FFAEM course. Dr Julia Harris. Consultant in A\&E Medicine, Chelsea and Westminster Hospital, London. Tel: 02087468000.

5. Royal Glamorgan Hospital FFAEM course. Dr Kamal, Accident and Emergency Department, Royal Glamorgan Hospital Ynysnaerdy, Llantrisant, CS52 2HQ. FFAEM course. Tel: 01443443443. 